\title{
Population Analysis of the Intermediate Complex States During B-Z Transition of Non-CG-repeat DNA Duplexes Induced by the Za Domain of Human ADAR1
}

\author{
Eun-Hae Lee, Yeo-Jin Seo, Hee-Eun Kim, Yeon-Mi Lee, Chong-Man Kim, ${ }^{\dagger, *}$ and Joon-Hwa Lee* \\ Department of Chemistry and Research Institute of Natural Science, Gyeongsang National University, \\ Gyeongnam 660-701, Korea. *E-mail: joonhwa@gnu.ac.kr \\ ${ }^{\dagger}$ Department of Industrial and Management Engineering, Myongji University, Gyeonggi 449-728, Korea \\ ${ }^{*}$ E-mail: chongman@mju.ac.kr \\ Received September 30, 2010, Accepted December 10, 2010
}

Key Words: NMR, Hydrogen exchange, Z-DNA, Confidence limit, ADAR1

\begin{abstract}
Z-DNA contains nucleic acid bases in alternating anti- and syn-conformations along the nucleotide chain and has only one groove that is similar to the minor groove of B-DNA. ${ }^{1-3} \mathrm{Z}-\mathrm{DNA}$ is in a higher energy conformation than B-DNA and is stabilized by negative supercoiling generated in vivo., ${ }^{2,3}$ Human ADAR1 has two left-handed Z-DNA binding domains at its $\mathrm{NH}_{2}$-terminus, $Z \alpha$ and $Z \beta$, preferentially binds $Z$-DNA, rather than B-DNA, with high binding affinity. ${ }^{4-6}$ The co-crystal structure of the $\mathrm{Z} \alpha$ domain of human ADAR1 ( $\left.\mathrm{Z} \alpha_{\mathrm{ADAR} 1}\right)$ bound to Z-DNA revealed that one monomeric $Z \alpha_{A D A R}$ domain binds to one strand of double-stranded DNA and a second $Z \alpha_{\mathrm{ADAR} 1}$ monomer binds to the opposite strand with two-fold symmetry with respect to the DNA helical axis. ${ }^{7}$ A structural study showed that $\mathrm{Z} \alpha_{\text {ADAR } 1}$ binds to the Z-conformation of non-CG-repeat DNA duplexes through a common structural feature rather than by a specific sequence or structural alternations. ${ }^{8}$ A previous NMR study on a d(CGCGCG) $)_{2}-Z \alpha_{\text {ADAR } 1}$ complex ${ }^{9}$ suggests an $a c$ tive-mono B-Z transition mechanism (see Fig. 1) in which the $Z \alpha_{\text {ADAR1 }}$ protein first binds to B-DNA and then converts it to left-handed Z-DNA, a conformation that is then stabilized by the additional binding of a second $Z \alpha_{\text {ADAR } 1}$ molecule.
\end{abstract}

Recently, we have reported NMR hydrogen exchange data of complexes between $Z \alpha_{\text {ADAR1 }}$ and the non-CG-repeat DNA duplexes, d(CACGTG) $)_{2}$ [referred to as CA6] or d(CGTACG $)_{2}$ [referred to as TA6], with a variety of protein-to-DNA $(\mathrm{P} / \mathrm{N})$ molar ratios. ${ }^{10}$ The $k_{\mathrm{ex}}$ data for the G4b of the CA6-Z $\alpha_{\text {ADAR } 1}$ complex and for the G2b of the TA6-Z $\alpha_{\text {ADAR } 1}$ complex showed significant changes as the Z-DNA fraction $\left(f_{\mathrm{Z}}\right)$ was increased (meaning that the $\mathrm{P} / \mathrm{N}$ ratio increased) (see Fig. 2). These changes of the $k_{\mathrm{ex}}$ data can be explained by the presence of mixtures of two imino protons from B-form DNA (referred to as B) and

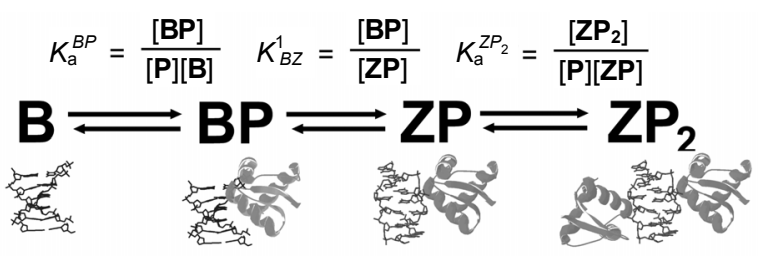

Figure 1. Active-mono B-Z transition mechanism of a 6-bp DNA duplex by two Z-DNA binding proteins. $\mathbf{B}$ and $\mathbf{Z}$ indicate the B-form and $Z$-form of the DNA duplex and $\mathbf{P}$ indicates the Z-DNA binding proteins.
B-DNA-Z $\alpha_{\text {ADAR1 }}$ complex (referred to as BP) in the imino peaks as given by Eq. 1: ${ }^{10}$

$$
k_{e x}=\frac{[B] k_{e x}^{B}+[B P] k_{e x}^{B P}}{[B]+[B P]}=k_{e x}^{B}+\frac{[B P]}{1-Z_{t}}\left(k_{e x}^{B P}-k_{e x}^{B}\right)
$$

where $k_{e x}^{B}$ and $k_{e x}^{B P}$ are the $k_{e x}$ of the imino protons for the $\mathbf{B}$ and
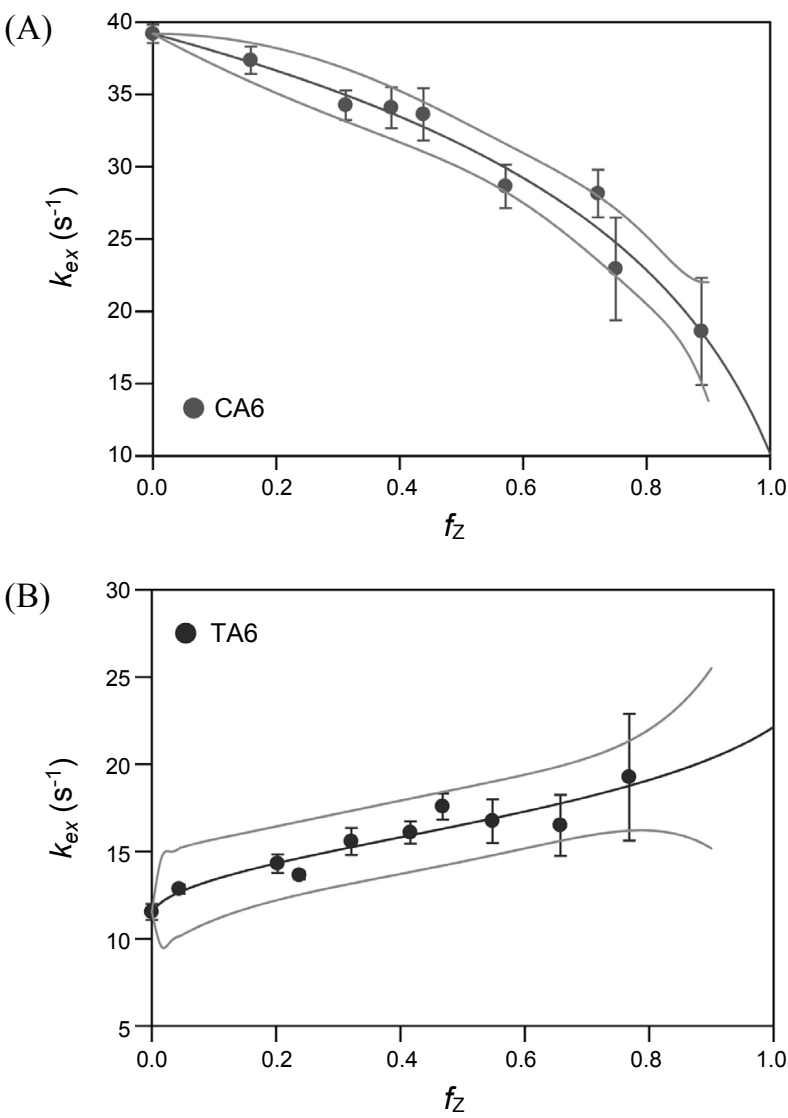

Figure 2. (A) The $k_{e x}$ values of the G4b imino proton for the CA6$\mathrm{Z} \alpha_{\text {ADAR } 1}$ complex determined at $25^{\circ} \mathrm{C}$ and (B) $k_{e x}$ values of the G2b imino proton for the TA6-Z $\alpha_{\text {ADAR } 1}$ complex determined at $15^{\circ} \mathrm{C}$ as a function of the $f_{\mathrm{Z}}$. Black solid lines are the best fit to Eq. 1, where the $k_{e x}$ data were weighted by the inverse of their variance. The grey lines indicate their upper and lower confidence limits $(95 \%$ confidence level). 
BP states, respectively, and $[\mathbf{B}]$ and $[\mathbf{B P}]$ are the concentrations of the $\mathbf{B}$ and $\mathbf{B P}$ states, $Z_{t}$ is the total concentration of Z-conformation. Thus, the correlation between the $k_{e x}$ and $f_{Z}$ data can be expressed by Eq. 2 as described in previous report: ${ }^{10}$

$$
\begin{aligned}
k_{e x}= & k_{e x}^{B}+\frac{\left(k_{e x}^{B P}-k_{e x}^{B}\right)}{2(1-\alpha)\left(1-f_{Z}\right)}\left\{1+\left(K_{B Z}^{1}-1\right) f_{Z}\right. \\
& \left.-\sqrt{\left(1+\left(K_{B Z}^{1}-1\right) f_{Z}\right)^{2}-4 K_{B Z}^{1}(1-\alpha) f_{Z}\left(1-f_{Z}\right)}\right\}
\end{aligned}
$$

where $K_{B Z}^{1}=[\mathbf{B P}] /[\mathbf{Z P}]$, and $\alpha\left(=K_{\mathrm{a}}^{Z P_{2}} / K_{\mathrm{a}}^{B P}\right)$ is the ratio of the association constants $\left(K_{\mathrm{a}}\right)$ of the $\mathbf{Z} \mathbf{P}_{\mathbf{2}}$ and $\mathbf{B P}$ complex states. In the previous report, ${ }^{10}$ the $\alpha$ (CA6: 1.42 ; TA6 13.9), $K_{B Z}^{1}$ (CA6: $0.4 \pm 0.1$; TA6: $6.3 \pm 3.1), k_{e x}^{B}\left(\mathrm{CA} 6: 39.2 \pm 0.6 \mathrm{~s}^{-1}\right.$; TA6: $\left.11.5 \pm 0.5 \mathrm{~s}^{-1}\right)$, and $k_{e x}^{B P}\left(\mathrm{CA} 6: 10.2 \pm 3.1 \mathrm{~s}^{-1}\right.$; TA6: $\left.22.2 \pm 5.3 \mathrm{~s}^{-1}\right)$ values of CA6 and TA6 complexed with $Z \alpha_{\text {ADAR } 1}$ were determined by curve fitting $k_{e x}$ of the imino protons as a function of $f_{Z}$ with Eq. 2 (Fig. 2). ${ }^{10}$

In order to estimate the reliability of the proposed model in the previous study, we performed the iterative non-linear curve fitting $k_{e x}$ of the imino protons in the CA6-Z $\alpha_{\text {ADAR1 }}$ and TA6$Z \alpha_{\text {ADAR } 1}$ complexes as a function of $f_{Z}$ with Eq. 2 using program Origin 7. The upper and lower confidence limits on the $k_{\mathrm{ex}}$ data of CA 6 and TA 6 complexed with $Z \alpha_{\text {ADAR1 }}$ were evaluated by iterative non-linear curve fitting and the $95 \%$ confidence bands of the $k_{\text {ex }}$ data are shown in Fig. 2. This result shows that the active-mono $\mathrm{B}-\mathrm{Z}$ transition mechanism, which was proposed in the previous study, ${ }^{10}$ is suitable approach to understand the DNA sequence descrimination step of the $Z \alpha_{A D A R}$ protein during $\mathrm{B}-\mathrm{Z}$ transition.

The relative population of each complex state (such as $\mathbf{B}, \mathbf{B P}$, $\mathbf{Z P}$, and $\mathbf{Z P} \mathbf{P}_{2}$ ) as a function of the $\mathrm{P} / \mathrm{N}$ ratio was determined from the $f_{Z}$ and $k_{\text {ex }}$ data, which were reported in previous study, ${ }^{10}$ as the following procedure. First, the $[\mathbf{B P}]$ values are calculated from the exchange data, $k_{e x}, k_{e x}^{B}$, and $k_{e x}^{B P}$,by using Eq. 3:

$$
[B P]=\frac{k_{e x}-k_{e x}^{B}}{k_{e x}^{B P}-k_{e x}^{B}}\left(1-Z_{t}\right)
$$

where $Z_{t}$ are determined from relative peak intensities of the imino proton resonances of the Z-form DNA. Second, the [B] values can be calculated by using the equation, $[\mathbf{B}]=1-Z_{t}-$ [BP]. Third, the concentration of the $\mathbf{Z P}$ state $([\mathbf{Z P}])$ is calculated from the flowing relation, $[\mathbf{Z P}]=[\mathbf{B P}] / K_{B Z}^{1}$. Forth, the concentration of the $\mathbf{Z} \mathbf{P}_{\mathbf{2}}$ state $\left(\left[\mathbf{Z P}_{\mathbf{2}}\right]\right)$ can be calculated by using the equation, $\left[\mathbf{Z P}_{\mathbf{2}}\right]=Z_{t}-[\mathbf{Z P}]$. The relative populations (including estimated errors) of the $\mathbf{B}, \mathbf{B P}, \mathbf{Z P}$, and $\mathbf{Z P}_{\mathbf{2}}$ states in the CA6-Z $\alpha_{\mathrm{ADAR} 1}$ and TA6-Z $\alpha_{\mathrm{ADAR} 1}$ complexes as a function of the $\mathrm{P} / \mathrm{N}$ ratio are shown in Fig. 3 and 4, respectively. Finally, the concentration of free $\mathrm{Z} \alpha_{\text {ADAR1 }}([\mathbf{P}])$ could be calculated by the Eq. 4:

$$
[P]=P_{t}-[B P]-[Z P]-2\left[Z P_{2}\right]
$$

where $P_{\mathrm{t}}$ is the total concentration of $\mathrm{Z} \alpha_{\mathrm{ADAR} 1}$.

From these concentrations, the association constants, $K_{\mathrm{a}}{ }^{B P}=$
(A)

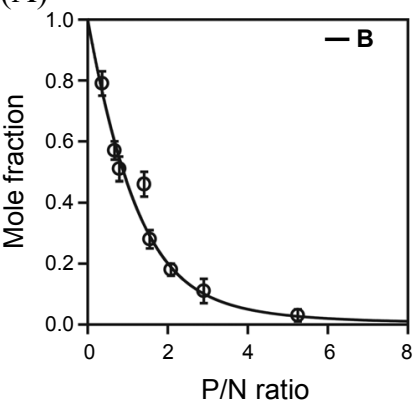

(B)

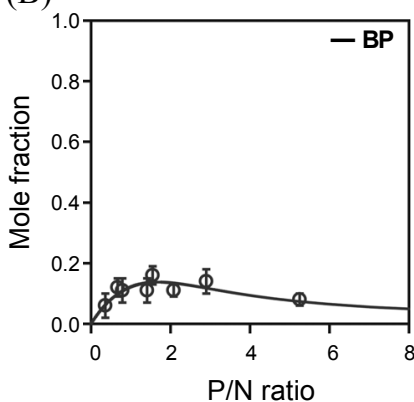

(C)

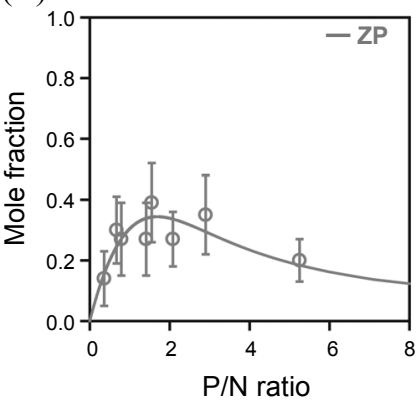

(D)

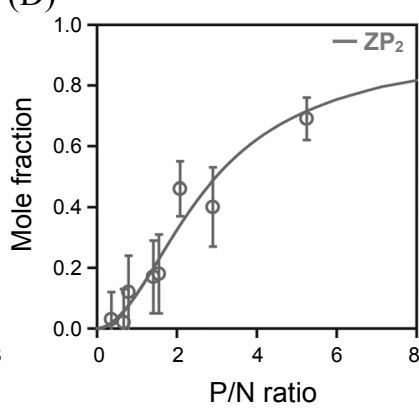

Figure 3. The relative populations of the (A) B, (B) BP, (C) ZP, and (D) $\mathbf{Z P}_{2}$ states within total DNA populations of the CA6 complexed with $\mathrm{hZ} \alpha_{\text {ADAR } 1}$ determined at $25^{\circ} \mathrm{C}$. Solid lines are simulated relative population of each complex state determined as described in text.

$[\mathbf{B P}] /[\mathbf{B}][\mathbf{P}]$ and $K_{\mathrm{a}}^{Z P_{2}}=\left[\mathbf{Z P}_{2}\right] /[\mathbf{Z P}][\mathbf{P}]$, for the CA6-Z $\alpha_{\text {ADAR } 1}$ and TA6-Z $\alpha_{\text {ADAR1 }}$ complexes were calculated. The $K_{\mathrm{a}}{ }^{B P}$ and $K_{\mathrm{a}}^{Z P_{2}}$ values of CA6-Z $\alpha_{\text {ADAR } 1}$ complex are $3.9 \pm 1.3 \times 10^{3}$ and $5.5 \pm 1.9 \times 10^{3}$, respectively. ${ }^{10}$ This means that, unlike the $\mathrm{d}(\mathrm{CGCGCG})_{2}-Z \alpha_{\text {ADAR } 1}$ complex, ${ }^{9}$ the $Z \alpha_{\text {ADAR } 1}$ protein can bind to the $\mathrm{B}$ and $\mathrm{ZP}$ complex states with similar binding affnity. The relative population of each complex state for the CA6-Z $\alpha_{A D A R 1}$ complex as a function of the $\mathrm{P} / \mathrm{N}$ ratio could be calculated from these association constants and equilibirum constants for B-Z transition and the results are shown in Fig. 3 (solid lines). It was observed that $[\mathbf{B}]$ was gradually decreased, but $[\mathbf{B P}]$ and $[\mathbf{Z P}]$ were increased as the $\mathrm{P} / \mathrm{N}$ ratio increased up to 2 (Fig. 3 ). In addition, the observation that $[\mathbf{B P}]$ is always smaller than $[\mathbf{Z P}]$ could be explained by the fact that $K_{B Z}^{1}<1$ (Fig. 3). When the $\mathrm{P} / \mathrm{N}$ ratio rose to 2 , the $\mathbf{Z P}_{2}$ complex was dominantly produced but $[\mathbf{B P}]$ and $[\mathbf{Z P}]$ were decreased as the $\mathrm{P} / \mathrm{N}$ ratio increased because the added $\mathbf{P}$ preferentially bound to the $\mathbf{Z P}$ complex rather than the $\mathbf{B}$ and $\mathbf{B P}$ (Fig. 3).

Similarly, the $K_{\mathrm{a}}^{B P}$ and $K_{\mathrm{a}}^{Z P_{2}}$ values of the TA6-Z $\alpha_{\mathrm{ADAR} 1}$ complex are $2.5 \pm 0.9 \times 10^{3}$ and $3.5 \pm 1.3 \times 10^{4}$, respectively. ${ }^{10}$ The relative population of each complex state for the TA6-Z $\alpha_{\text {ADAR } 1}$ complex as a function of the $\mathrm{P} / \mathrm{N}$ ratio are shown in Fig. 4 (solid lines). Similar to the CA6-Z $\alpha_{\text {ADAR } 1}$ complex In the both complexes, it was observed that $[\mathbf{B}]$ was gradually decreased, but $[\mathbf{B P}]$ and $[\mathbf{Z P}]$ were increased as the $\mathrm{P} / \mathrm{N}$ ratio increased up to 2 (Fig. 4). However, contrast to the CA6-Z $\alpha_{\text {ADAR1 }}$ complex, it was observed that $[\mathbf{B P}]$ is always larger than $[\mathbf{Z P}]$, indicating that $K_{B Z}^{1}>1$, (Fig. 4). When the $\mathrm{P} / \mathrm{N}$ ratio rose to 2 , the $\mathbf{Z P 2}$ complex was dominantly produced but $[\mathbf{B P}]$ and $[\mathbf{Z P}]$ were decreased as the $\mathrm{P} / \mathrm{N}$ ratio increased like CA6 (Fig. 4).

Interestingly, the simulated population (solid line in Fig. 3 and 
(A)

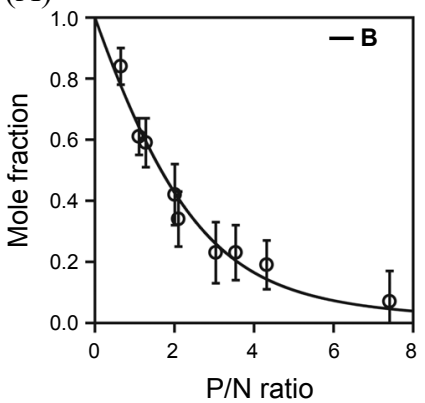

(B)

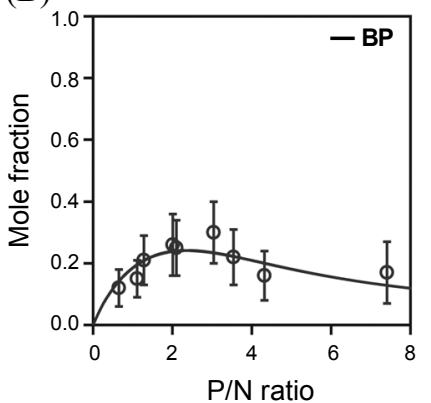

(C)

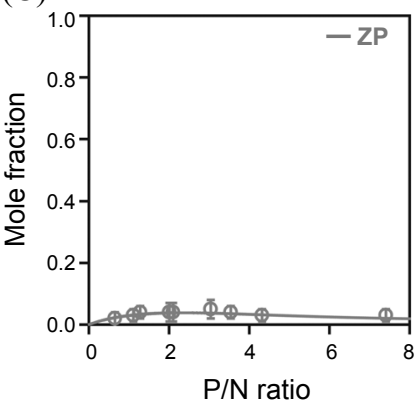

(D)

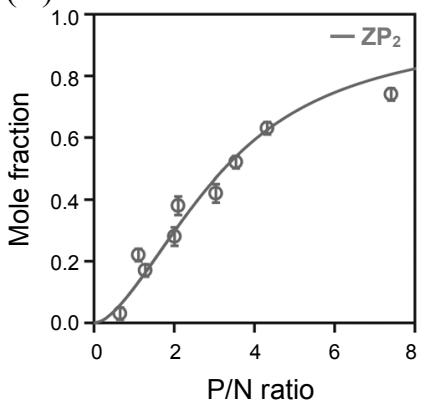

Figure 4. The relative populations of the (A) B, (B) BP, (C) ZP, and (D) $\mathbf{Z P}_{\mathbf{2}}$ states within total DNA populations of the TA6 complexed with $\mathrm{hZ} \alpha_{\text {ADARI }}$ determined at $15^{\circ} \mathrm{C}$. Solid lines are simulated relative population of each complex state determined as described in text.

4) of each complex data determined from the association constants and equilibirum constants for B-Z transition well matched to the experimental value (symbol in Fig. 3 and 4) determined from the $f_{Z}$ and $k_{\text {ex }}$ data. This indicates that our approach is able to calculate successfully the concentrations of the intemediate state during B-Z transition. This correlation between the relative population of each complex state and the $\mathrm{P} / \mathrm{N}$ ratio as shown
Fig. 3 and 4 can explain how the $Z \alpha_{A D A R 1}$ protein recognizes the $\mathrm{d}(\mathrm{CGCGCG})$ sequence from d(CACGTG) and d(CGTACG) sequences in a long genomic DNA.

In summary, we derived the relative population of each complex state, which is thought to be produced during $\mathrm{B}-\mathrm{Z}$ transition induced by $Z \alpha_{A D A R 1}$, as a function of the $\mathrm{P} / \mathrm{N}$ ratio. This approach provides the insight into the active $\mathrm{B}-\mathrm{Z}$ transition mechanism and DNA sequence discrimination step of human Z-DNA binding protein, ADAR1.

Acknowledgments. This Work was supported by the National Research Foundation of Korea Grants [2010-0014199; NRFC1ABA001-2010-0020480 to J.-H.L.] funded by the Korean Government (MEST).

\section{References}

1. Rich, A.; Nordheim, A.; Wang, A. H. Annu. Rev. Biochem. 1984, 53, 791.

2. Herbert, A.; Rich, A. J. Biol. Chem. 1996, 271, 11595.

3. Herbert, A.; Rich, A. Genetica 1999, 106, 37.

4. Herbert, A. G.; Rich, A. Nucleic Acids Res. 1993, 21, 2669.

5. Herbert, A.; Alfken, J.; Kim, Y. G.; Mian, I. S.; Nishikura, K.; Rich, A. Proc. Natl. Acad. Sci. USA 1997, 94, 8421.

6. Herbert, A.; Schade, M.; Lowenhaupt, K.; Alfken, J.; Schwartz, T.; Shlyakhtenko, L. S.; Lyubchenko, Y. L.; Rich, A. Nucleic Acids Res. 1998, 26, 3486.

7. Schwartz, T.; Rould, M. A.; Lowenhaupt, K.; Herbert, A.; Rich, A. Science 1999, 284, 1841 .

8. Ha, S. C.; Choi, J.; Hwang, H. Y.; Rich, A.; Kim, Y. G.; Kim, K. K. Nucleic Acids Res. 2009, 37, 629.

9. Kang, Y.-M.; Bang, J.; Lee, E.-H.; Ahn, H.-C.; Seo, Y.-J.; Kim, K. K.; Kim, Y.-G.; Choi, B.-S.; Lee, J.-H. J. Am. Chem. Soc. 2009 , 131,11485 .

10. Seo, Y.-J.; Ahn, H.-C.; Lee, E.-H.; Bang, J.; Kang, Y.-M.; Kim, H.-E.; Lee, Y.-M.; Kim, K.; Choi, B.-S.; Lee, J.-H. FEBS Lett. 2010, 584,4344 . 